\title{
Clinical Viewpoint
}

\section{Evidence Based Arm Care: The Throwers 10 Revisited}

\author{
Michael Mullaney, DPT, SCS ${ }^{1}$, Stephen Nicholas, MD², Timothy Tyler, PT, ATC³, Takumi Fukunaga, DPT, ATC, CSCS ${ }^{2}$ \\ Malachy McHugh, $\mathrm{PhD}^{2}$ \\ ${ }^{1}$ Nicholas Institute of Sports Medicine \& Athletic Trauma; Mullaney \& Associates Physical Therapy, LLC, ${ }^{2}$ Nicholas Institute of Sports Medicine \& \\ Athletic Trauma, ${ }^{3}$ Nicholas Institute of Sports Medicine \& Athletic Trauma; Professional Physical Therapy \\ Keywords: shoulder, throwers, arm care \\ https://doi.org/10.26603/001c.29900
}

\section{International Journal of Sports Physical Therapy}

Vol. 16, Issue 6, 2021

\section{THE EVOLUTION OF BASEBALL ARM CARE}

Over the past 40 years sports medicine physicians, physical therapists and performance experts have continually worked to advance treatment paradigms for the throwing athlete. The progression of evidence-based arm care has taken generations of innovators to get to where we are today. In 1983, Dr. Frank Jobe pioneered the original EMG study on the deltoids, subscapularis and what they referred to as the "SIT" muscles (supraspinatus, infraspinatus, and teres minor) during the pitching motion. ${ }^{1}$ This work continued to advance through the 1980s and early 1990s with Jobe et al. ${ }^{1}$ and DiGiovine et al. ${ }^{2}$ giving clinicians a better understanding of the muscle activity and performance demands of the entire upper extremity during the pitching motion. This work set the stage for researchers like Mosely et al. ${ }^{3}$, Blackburn et al. ${ }^{4}$ and Townsend et al. ${ }^{5}$ to investigate which exercises would be most beneficial for the throwing athlete, allowing innovators like Kevin Wilk and James Andrews to develop the Thrower's Ten Exercise Program in $1991 .^{6}$

In 2011, Wilk et al. ${ }^{7}$ introduced the "Advanced Thrower's Ten”. This expanded program incorporated throwing motion-specific exercises and movement patterns performed in a discrete series, utilizing principles of coactivation, high-level neuromuscular control, dynamic stabilization, muscular facilitation, strength, endurance, and coordination, which all serve to restore muscle balance and symmetry in the overhead throwing athlete. ${ }^{7}$ The evolution of these arm care programs has been an asset to the baseball community, offering the opportunity for pre-season and off-season strengthening for injury prevention and sports performance.

The Yokahama Baseball-9 (YKB-9) and the modified Yokahama Baseball-9 (mYKB-9) are prime examples of an arm care program that has been researched and modified to show its efficacy. ${ }^{8,9}$ Although the exercises do not appear to all be evidence-based, the testing and modification of the program has shown desired effects. The goal of any arm care program is to not only show strength improvements, but also show the desired effects on injuries. Evolving the arm care programs needs to include a research-based program that can offer in-season strengthening and maintenance that can easily be performed in any setting, on the road, with minimal equipment.

\section{BUILDING ON THE GOLD STANDARD}

At the Nicholas Institute of Sports Medicine and Athletic Trauma (NISMAT), our founder James A. Nicholas, MD was paramount in offering evidence-based medicine that addressed not only the injury, but the athlete. In 1976, Dr. Nicholas developed the concept of linkage by highlighting the importance of proximal stability for distal mobility. 10 This concept has been the catalyst for developing the NISMAT Arm Care program. To maintain a healthy throwing arm, we needed to provide evidence-based exercises that not only address strength but also address flexibility and endurance from the trunk to the hand.

The goals of developing the NISMAT Arm Care program were: (1) Exercises should be evidence-based. Focused exercises that are evidence-based will maximize the efficiency of the arm care program. (2) Develop a program that considers the concept of linkage described by James A. Nicholas. (3) Develop a program that is portable and can be performed in any setting. In today's baseball lifestyle, players, trainers, and parents are always on the road with minimal access to high level, expensive strength equipment. This program was designed to utilize elastic-resistance exercises with no additional equipment required.

Developing this NISMAT Arm Care Program was a threestep process. Step 1: The Arm Care team first reviewed the early pioneering EMG studies identifying which muscles were activated during the pitching motion. ${ }^{1,2}$ This enabled our team to develop a list of muscles that needed to be addressed in an arm care program. Step 2: The team then identified which exercises have sufficient evidence to support their use for training specific muscle groups. A review of the EMG literature was performed to find the top exercises that would address these specific muscles activated during pitching. During this step we determined there was

\footnotetext{
a Corresponding Author:

Michael Mullaney DPT, SCS

Mullaneypt@gmail.com
} 
Table 1.

\begin{tabular}{|c|c|c|}
\hline Exercise & Muscle Activated & Max Activation Pitching Phase \\
\hline Push-up Plus & Serratus Anterior & Late Cocking Phase \\
\hline $\begin{array}{l}\text { Bilateral External Rotation with Scapular } \\
\text { Retraction }\end{array}$ & Lower Trapezius & Acceleration $\rightarrow$ Deceleration \\
\hline Standing horizontal abduction with neutral & Posterior Deltoid & Acceleration $\rightarrow$ Deceleration \\
\hline Lawnmower & $\begin{array}{l}\text { Lower Trapezius } \\
\text { Posterior Deltoid }\end{array}$ & $\begin{array}{l}\text { LT: Acceleration } \rightarrow \text { Deceleration } \\
\text { PD: Acceleration } \rightarrow \text { Deceleration }\end{array}$ \\
\hline Standing diagonal band pull-apart & $\begin{array}{l}\text { Supraspinatus } \\
\text { Upper Trapezius } \\
\text { Middle Trapezius } \\
\text { Lower Trapezius } \\
\text { Posterior Deltoid }\end{array}$ & $\begin{array}{c}\text { SS: Early Cocking } \rightarrow \text { Acceleration } \\
\text { UT: Early Cocking, Acceleration \& } \\
\text { Deceleration } \\
\text { MT: Acceleration } \\
\text { LT: Acceleration } \rightarrow \text { Deceleration } \\
\text { PD: Acceleration } \rightarrow \text { Deceleration }\end{array}$ \\
\hline Standing row $+90 / 90 \mathrm{ER}$ & Infraspinatus Teres Minor & $\begin{array}{c}\text { Infraspinatus = Late Cocking } \\
\text { T.M = Late Cocking } \rightarrow \text { Deceleration }\end{array}$ \\
\hline Side Plank with ER & Infraspinatus & Late Cocking \\
\hline Shoulder IR at $90 / 90$ Position & Subscapularis & Late Cocking $\rightarrow$ Acceleration \\
\hline Standing Scaption & $\begin{array}{l}\text { Supraspinatus } \\
\text { Middle Deltoid } \\
\text { Teres Minor }\end{array}$ & $\begin{array}{l}\text { SS: Early Cocking } \rightarrow \text { Acceleration } \\
\text { MD: Deceleration } \\
\text { T.M: Late Cocking } \rightarrow \text { Deceleration }\end{array}$ \\
\hline Wall Walk with Elastic Resistance & Infraspinatus & Late Cocking \\
\hline Seated Forearm Pronation with Theraband/CLX & $\begin{array}{l}\text { Pronator Teres } \\
\text { Flexor Digitorum } \\
\text { Superficialis }\end{array}$ & $\begin{array}{c}\text { PT: Acceleration } \\
\text { FDS: Acceleration } \rightarrow \text { Deceleration }\end{array}$ \\
\hline Wrist UInar Deviation with Theraband/CLX & Flexor Carpi Ulnaris & Acceleration \\
\hline
\end{tabular}

little evidence supporting exercises for the flexor pronator mass. Additionally, no EMG studies have examined which muscles are activated during the commonly used pull-apart exercises. Step 3: The final step was to fill the gap in the literature by providing evidence for exercises that are presumed to target muscles involved in the throwing motion. In this current issue of the International Journal of Sport Physical Therapy, two of these studies have been included to add evidence to these prescribed exercises.

\section{NISMAT ARM CARE PROGRAM}

The NISMAT ARM Care program addresses musculoskeletal strength and mobility during each of the stages of pitching. Below you will find each exercise included in the NISMAT ARM Care program, the target muscle or movement, and the phase of pitching in which the specific muscle is working at its peak. This breakdown can also be found in Table 1 . Appendix A has photos and a link to the formal program.

\section{PUSH-UP PLUS (OPTIONAL BAND) \\ HTTPS://VIDEOS.FILES.WORDPRESS.COM/3DPRVTMI/ PUSHUP-PLUS HD.MP4}

This exercise was chosen to address serratus anterior. The scapular muscles play a large role in the stability and foundation of the throwing arm. From the late cocking to the deceleration phase the serratus anterior maintains an EMG level between 51 and 106\% Maximum Volitional Contraction (MVC) with the peak MVC occurring during late cocking. ${ }^{2}$ To help address the serratus anterior we chose the push-up plus. Multiple studies rank this exercise as the most effective serratus anterior exercises reaching between 90 to $104 \%$ MVC. ${ }^{11-13}$ The NISMAT Arm Care program also recommends incorporating the use of elastic resistance to increase the MVC while performing the exercise. ${ }^{3,11}$

\section{BILATERAL EXTERNAL ROTATION WITH SCAPULAR RETRACTION HTTPS://VIDEOS.FILES.WORDPRESS.COM/ ZKYLU4KB/BL-ER-SCAP-RETRACTION HD.MP4}

This exercise was chosen to address lower trapezius muscle strengthening. During the pitching motion, the lower trapezius muscle activity reaches between 76-78\% MVC during the acceleration and deceleration stages. ${ }^{2,14}$ McCabe et al. ${ }^{14}$ highlighted this exercise as one of the best exercises for activating lower trapezius activity while minimizing upper trapezius activity.

\section{STANDING HORIZONTAL ABDUCTION WITH NEUTRAL HAND POSITION \\ HTTPS://VIDEOS.FILES.WORDPRESS.COM/S2NBIVY1/ HORZ-ABD-NEUTRAL_HD.MP4}

This exercise was chosen to address posterior deltoid strengthening. During the acceleration and deceleration stages of pitching, the posterior deltoid muscle activity reaches between $60-68 \%$ MVC. $^{2}$ Townsend et al. ${ }^{5}$ found this exercise to isolate the posterior deltoid and infraspinatus. The posterior deltoid reaches levels of 93\% MVC during this exercise. ${ }^{5}$ 
LAWNMOWER HTTPS://VIDEOS.FILES.WORDPRESS.COM/ MA5YTB8T/LAWNMOWER_HD.MP4

This exercise was chosen to address both lower trapezius and posterior deltoid strengthening. As stated previously, lower trapezius muscle activity can reach as high as $78 \%$ MVC, while the posterior deltoid can reach up to 68\% MVC during acceleration and deceleration. ${ }^{2}$ The lawnmower exercise has been shown to reach activation levels of the lower trapezius as high as $30 \%$ and posterior deltoid up to $32 \%$ MVC. 15,16

\section{STANDING DIAGONAL BAND PULL-APART HTTPS://VIDEOS.FILES.WORDPRESS.COM/IRERWSKE/ STANDING-DIAGONAL-PULL-APART HD.MP4}

This exercise was chosen to address supraspinatus, middle trapezius, and posterior deltoid. The supraspinatus activity can reach $60 \%$ MVC and middle trapezius $68 \%$ MVC from cocking to acceleration while posterior deltoid activity can reach $68 \%$ MVC from acceleration to deceleration. ${ }^{2}$ Fukunaga et al. ${ }^{17}$ highlighted this exercise with a neutral grip can elevate MVC activity in supraspinatus (60\%), middle trapezius (58\%), upper trapezius (64\%) and posterior deltoid (54\%).

\section{STANDING ROW WITH 90/90 EXTERNAL ROTATION HTTPS://VIDEOS.FILES.WORDPRESS.COM/TAXBOYZF/ STANDING-ROW-9090ER-EDIT.MP4}

This exercise was chosen for activation of the infraspinatus and teres minor. During the pitching motion, the infraspinatus peaks muscle activation during the late cocking phase (74\%), while the teres minor muscle activity peaks during the deceleration stage (84\%). ${ }^{2}$ This exercise has been shown to activate the infraspinatus between 50-88\% MVC, while teres minor activation will reach a lower level of $39 \%$ MVC. 5,12,18,19 The NISMAT Arm Care program encourages this exercise to start with a scapular retraction during the row. Schacter et al. ${ }^{20}$ showed that external rotation strength is higher when initiated with scapular stabilization.

\section{SIDE PLANK WITH EXTERNAL ROTATION HTTPS://VIDEOS.FILES.WORDPRESS.COM/OOPDXNYZ/ SIDEPLANK-SHOULDER-ER HD.MP4}

This exercise was chosen for activation of infraspinatus, supraspinatus, teres minor and posterior deltoid. During the pitching motion the infraspinatus reaches its peak MVC during late cocking (74\%), supraspinatus reaches its peak MVC during early cocking (60\%), teres minor reaches its peak MVC during deceleration (84\%) and posterior deltoid reaches peak during acceleration (68\%). ${ }^{2,8,19}$ Historically, the side-lying external rotation exercise has been shown to activate these muscles: infraspinatus $42-62 \%$ MVC, supraspinatus $51 \%$ MVC, teres minor $67 \%$ MVC and posterior deltoid 52\% MVC. ${ }^{12,18}$ The NISMAT Arm Care program, based on Krause et al. ${ }^{21}$ recommends using a side plank position to elevate the muscle activity in posterior deltoid and infraspinatus.
SHOULDER INTERNAL ROTATION AT 90/90 POSITION HTTPS://VIDEOS.FILES.WORDPRESS.COM/IYTTXAVC/ SHOULD-IR-9090 HD.MP4

This exercise was chosen for activation of the subscapularis. Subscapularis activation reaches its peak MVC during the acceleration stage of pitching (115\%). ${ }^{2}$ This exercise has been shown to reach between $65-71 \%$ MVC. ${ }^{12,22}$ The NISMAT Arm Care program recommends performing scapular stabilization prior to performing this exercise. Schacter et al. $^{20}$ showed improved internal rotation muscle activation when performing scapular stabilization.

\section{STANDING SCAPTION \\ HTTPS://VIDEOS.FILES.WORDPRESS.COM/ON2YOW04/ STANDING-SCAPTION_HD.MP4}

This exercise was chosen for activation of the supraspinatus, middle deltoid, and teres minor. The supraspinatus reaches $60 \%$ MVC from cocking to acceleration, middle deltoid reaches 59\% MVC and teres minor reaches $84 \%$ MVC during deceleration. ${ }^{2}$ A review of the literature supports the scaption exercise as a general shoulder strengthening exercise. ${ }^{12,18,22}$ The highest activation occurs in the supraspinatus 32-64\% MVC, middle deltoid 38-52\% MVC, and teres minor 39-110\% MVC. ${ }^{12,18,22,23}$

\section{WALL WALKS HTTPS://VIDEOS.FILES.WORDPRESS.COM/ MCWON5HO/TBAND-WALL-WALK HD.MP4}

This exercise was chosen for activation of infraspinatus. During the pitching motion the infraspinatus reaches its peak MVC during late cocking (74\%). ${ }^{2}$ This exercise increased EMG activity over $21 \%$ MVC between $60-90^{\circ}$ of shoulder flexion, allowing for a safe option for infraspinatus strengthening without placing the shoulder in an impingement position. ${ }^{24}$

\section{SEATED FOREARM PRONATION WITH THERABAND HTTPS://VIDEOS.FILES.WORDPRESS.COM/VMRTKSZR/ SEATED-FOREARM-PRO HD.MP4}

This exercise was chosen for activation of the pronator teres. The pronator teres reaches $88 \%$ MVC and flexor digitorum superficialis reaches $80 \%$ MVC during the acceleration stage of pitching. ${ }^{2}$ Fukunaga et al. ${ }^{25}$ showed the pronation using elastic resistance activated pronator teres $73 \%$ MVC and the flexor digitorum superficialis 64\% MVC.

\section{WRIST ULNAR DEVIATION WITH ELASTIC RESISTANCE HTTPS://VIDEOS.FILES.WORDPRESS.COM/LOSYX9R7/ WRIST-ULNAR-DEV_HD.MP4}

This exercise was chosen for activation of flexor carpi ulnaris. Flexor carpi ulnaris reaches $112 \%$ MVC during the acceleration stage of pitching. ${ }^{2}$ The flexor carpi ulnaris is also considered a secondary stabilizer of the ulnar collateral ligament. Fukunaga et al. ${ }^{25}$ showed the ulnar deviation with elastic resistance reached $40 \%$ MVC. 


\section{STANDING CROSSBODY ADDUCTION POSTERIOR SHOULDER STRETCH (SHOULDER AGAINST WALL) HTTPS://VIDEOS.FILES.WORDPRESS.COM/8R58TIFG/ STAND-POST-SHOULD-STRETCH_HD.MP4}

This exercise was chosen to improve and maintain posterior shoulder tightness. Escamilla et al. ${ }^{26}$ highlighted the advantages of this internal rotation for maintaining internal rotation range of motion loss between innings. ${ }^{26}$ The NISMAT arm care program recommends performing this against a wall or side of dugout to maintain a more stable scapula.

\section{QUADRUPED THORACIC ROTATION HTTPS://VIDEOS.FILES.WORDPRESS.COM/W2UU6V2X/ OUAD-THORACIC-ROT1 HD.MP4}

This exercise was chosen to improve thoracic mobility. Hip shoulder separation is related to trunk velocity and ultimately pitch velocity. ${ }^{27}$ Therefore, training interventions to improve pelvic-trunk axial dissociation may increase maximal trunk rotation velocity. ${ }^{27}$

\section{DISCUSSION}

The evolution of arm care for the baseball athlete has continued to gain evidence over the past 40 years. What was originally developed from clinical experience has gradually evolved over the years to be a more evidence-based approach to arm care for the pitcher. We have gained a better understanding of the muscular performance demands through the EMG studies of the pitching motion. ${ }^{1,2}$ As clinicians we are continually looking to prepare our athletes for peak performance and injury prevention.

Arm care programs are designed to offer both a performance component and injury prevention. Sakata et al. ${ }^{8}$ highlighted the success of the YKB-9 program at not only improving muscular variables, but the YKB-9 program showed a $49 \%$ decrease in medial elbow pain in youth pitchers 8-11 years old. The YKB-9 consisted of 9 strengthening exercises with no more resistance than the player's glove as well as 9 stretching exercises. ${ }^{8}$ Both groups of exercises addressed upper extremity, trunk and hips. ${ }^{8}$ Understanding the limitations of an 18-exercise program, the mYKB-9 was slimmed down to 9 exercises, and after a 1-year follow-up, a reduction in both shoulder and elbow pain was noted in the players that used the program. ${ }^{9}$
Although not all arm care programs have gone through the rigors of studying their effectiveness in the field, these studies by Sakata et al. ${ }^{8,9}$ highlight the potential impact of using arm care interventions. By simplifying the YKB-9 program Sakata et al. ${ }^{9}$ was able to increase the arm care program compliance rate from $54 \%$ to $74 \%$ showing greater gains in those who were compliant. Arm care programs need to be well thought out with consideration for strength and mobility, but also the level of complexity associated with the program. Programs that are too long, need extra equipment or various weights, offer a potential roadblock to compliance. Our team certainly realizes there are many exercises to choose from when developing an arm care program. The NISMAT Arm Care program was developed to offer the best evidence-based arm care with nothing more than elastic resistance.

The evolution of arm care programs has been an exciting journey. Early pioneers broke down the EMG activity of each muscle during each pitching phase, which led to the development of the original gold standard of arm care programs: the Thrower's Ten. It has been exciting to see the evolution of many of these programs by their own creators. Based on experience and science, Kevin Wilk and James Andrews improved their original Thrower's Ten and created a program more fit for the throwing athlete in the Advanced Thrower's Ten. ${ }^{7}$ Jun Sakata created a successful arm care program in the mYKB-9 program; however, he saw the length of the program as a potential flaw. 8,9 The evolution of that program led to a shorter program with improved potential for compliance. Arm care is an evolving process that needs to be re-evaluated based on the continually changing literature. The NISMAT Arm Care program is based on current EMG research using no more than elastic resistance and addressing each of the key components of the pitching motion. Our team has accomplished our 3 goals for developing the NISMAT Arm Care program. We developed a portable, research-based program, capturing the linkage component of the pitching motion. We look forward to the future of the NISMAT Arm Care program as it evolves with science.

Submitted: October 01, 2021 CST, Accepted: November 01, 2021 CST 


\section{REFERENCES}

1. Jobe FW, Tibone JE, Perry J, Moynes D. An EMG analysis of the shoulder in throwing and pitching. $\mathrm{Am}$ J Sport Med. 1983;11(1):3-5. doi:10.1177/03635465830 $\underline{1100102}$

2. Digiovine NM, Jobe FW, Pink M, Perry J. An electromyographic analysis of the upper extremity in pitching. J Shoulder Elbow Surg. 1992;1(1):15-25. doi:1 0.1016/s1058-2746(09)80011-6

3. Moseley JB Jr, Jobe FW, Pink M, Perry J, Tibone J. EMG analysis of the scapular muscles during a shoulder rehabilitation program. Am J Sports Med Mar-Apr. 1992;20(2):128-134.

4. Blackburn TA. EMG analysis of posterior rotator cuff exercises. J Athl Train. 1990;25:40-45.

5. Townsend H, Jobe FW, Pink M, Perry J. Electromyographic analysis of the glenohumeral muscles during a baseball rehabilitation program. Am J Sports Med. 1991;19(3):264-272.

6. Wilk KE, Andrews JR, Arrigo CA, et al. Preventive and Rehabilitative Exercises for the Shoulder and Elbow. 5th ed. Birmingham, AL: American Sports Medicine Institute; 1997.

7. Wilk KE, Yenchak AJ, Arrigo CA, Andrews JR. The Advanced Throwers Ten Exercise Program: a new exercise series for enhanced dynamic shoulder control in the overhead throwing athlete. Phys Sportsmed. 2011;39(4):90-97. doi:10.3810/psm.2011.1 $\underline{1.1943}$

8. Sakata J, Nakamura E, Suzuki T, et al. Efficacy of a Prevention Program for Medial Elbow Injuries in Youth Baseball Players. Am J Sports Med. 2018;46(2):460-469. doi:10.1177/0363546517738003

9. Sakata J, Nakamura E, Suzuki T, et al. Throwing Injuries in Youth Baseball Players: Can a Prevention Program Help? A Randomized Controlled Trial. Am J Sports Med. 2019;47(11):2709-2716. doi:10.1177/0363 $\underline{546519861378}$

10. Nicholas JA, Strizak AM, Veras G. A study of thigh muscle weakness in different pathological states of the lower extremity. Am J Sports Med. 1976;4(6):241-248. doi:10.1177/036354657600400602

11. Decker MJ, Hintermeister RA, Faber KJ, Hawkins RJ. Serratus anterior muscle activity during selected rehabilitation exercises. Am J Sports Med. 1999;27(6):784-791. doi:10.1177/03635465990270061 601
12. Edwards PK, Ebert JR, Littlewood C, Ackland T, Wang A. A Systematic Review of Electromyography Studies in Normal Shoulders to Inform Postoperative Rehabilitation Following Rotator Cuff Repair. J Orthop Sports Phys Ther Dec. 2017;47(12):931-944.

13. Batbayar Y, Uga D, Nakazawa R, Sakamoto M. Effect of various hand position widths on scapular stabilizing muscles during the push-up plus exercise in healthy people. J Phys Ther Sci. 2015;27(8):2573-2576. doi:10.1589/jpts.27.2573

14. McCabe RA, Orishimo KF, McHugh MP, Nicholas SJ. Surface electromygraphic analysis of the lower trapezius muscle during exercises performed below ninety degrees of shoulder elevation in healthy subjects. N Am J Sports Phys Ther. 2007;2(1):34-43.

15. Tsuruike M, Ellenbecker TS. Serratus anterior and lower trapezius muscle activities during multi-joint isotonic scapular exercises and isometric contractions. J Athl Train. 2015;50(2):199-210. doi:1 $\underline{0.4085 / 1062-6050-49.3 .80}$

16. Kibler WB, Sciascia AD, Uhl TL, Tambay N, Cunningham T. Electromyographic analysis of specific exercises for scapular control in early phases of shoulder rehabilitation. Am J Sports Med. 2008;36(9):1789-1798. doi:10.1177/036354650831628 1

17. Fukunaga T, Fedge C, Tyler T, Mullaney M, Schmitt B, et al. Band Pull-Apart Exercise: Effects of Movement Direction and Hand Position on Shoulder Muscle Activity. Submitted for publication Int J Sports Phys Ther. 2022.

18. Reinold MM, Wilk KE, Fleisig GS, et al. Electromyographic analysis of the rotator cuff and deltoid musculature during common shoulder external rotation exercises. J Orthop Sports Phys Ther. 2004;34(7):385-394. doi:10.2519/jospt.2004.34.7.385

19. Nakamura Y, Tsuruike M, Ellenbecker TS. Electromyographic Activity of Scapular Muscle Control in Free-Motion Exercise. J Athl Train. 2016;51(3):195-204. doi:10.4085/1062-6050-51.4.10

20. Schachter AK, McHugh MP, Tyler TF, et al. Electromyographic activity of selected scapular stabilizers during glenohumeral internal and external rotation contractions. J Shoulder Elbow Surg. 2010;19(6):884-890. doi:10.1016/j.jse.2010.05.015 
21. Krause DA, Dueffert LG, Postma JL, Vogler ET, Walsh AJ, Hollman JH. Influence of Body Position on Shoulder and Trunk Muscle Activation During Resisted Isometric Shoulder External Rotation. Sports Health. 2018;10(4):355-360. doi:10.1177/1941738118 $\underline{769845}$

22. Myers JB, Pasquale MR, Laudner KG, Sell TC, Bradley JP, Lephart SM. On-the-Field ResistanceTubing Exercises for Throwers: An Electromyographic Analysis. J Athl Train. 2005;40(1):15-22.

23. Reinold MM, Macrina LC, Wilk KE, et al. Electromyographic analysis of the supraspinatus and deltoid muscles during 3 common rehabilitation exercises. J Athl Train. 2007;42(4):464-469.

24. Ellenbecker T, Piescynski T, Bailie DS, Page P. Analysis of rotator cuff and scapular muscle activation during elastic resistance, external rotation oscillation and band walk exercises (SPL3). J Ortho Sports Phys Ther. 2012;42(1):A41 Combined Sections Meeting of the American Physical Therapy Association. Chicago, Il.
25. Fukunaga T, Fedge C, Tyler T, Mullaney M, Schmitt B, et al. Flexor-Pronator Mass Training Exercises Selectively Activate Forearm Musculature. Submitted for publication Int J Sports Phys Ther. 2022.

26. Escamilla RF, Yamashiro K, Mikla T, Collins J, Lieppman K, Andrews JR. Effects of a Short-Duration Stretching Drill After Pitching on Elbow and Shoulder Range of Motion in Professional Baseball Pitchers. Am J Sports Med. 2017;45(3):692-700. doi:10.1177/036 $\underline{3546516671943}$

27. Bullock GS, Strahm J, Hulburt TC, Beck EC, Waterman BR, Nicholson KF. The relationship of range of motion, hip shoulder separation and pitching kinematics. Int J Sports Phys Ther. 2020;15(6):1119-1128. doi:10.26603/ijspt20201119 


\section{APPENDIX A}

\section{NISMAT ARM CARE PROGRAM EXERCISES}

\section{https://nismat.org/education/injury-prevention/exercise-} programs/nismat-arm-care-program/

\section{PUSH-UP PLUS (OPTIONAL BAND)}

Wrap a resistance band around your torso at the level of mid-back and assume plank position on hands and toes, with straight elbows and feet together. Bend your elbows to lower your chest, then push up by straightening your elbows. Once your elbows are straight, push further down to bring your shoulder blades forward.

\section{BILATERAL ER WITH SCAPULAR RETRACTION}

While sitting or standing, tie a loop with a resistance band and wrap around both wrists. With elbows bent to right angles, pull the looped band apart by moving your hands out. Move your shoulder blades back as you move your hands apart.

\section{STANDING HORIZONTAL ABDUCTION WITH NEUTRAL}

While standing, hold two ends of a resistance band with your palms facing inward. Keeping your elbows straight, move your arms out to pull the band apart while moving your shoulder blades back, then slowly move your arms in towards the middle.

\section{STANDING DIAGONAL BAND PULL-APART}

While standing, hold two ends of a resistance band. Keeping your elbows straight, move one arm diagonally up and out while you move the other arm diagonally down and out. After the number of repetitions in this pattern, switch directions for your arms and repeat.

\section{STANDING ROW + 90/90 ER}

Anchor the middle of a resistance band on a secure object at about waist height. Stand back so the band is taut as you hold both ends of the band. Perform a row by pulling the band and bringing your elbows back to the level of your chest. With your elbows bent at right angles, twist your arms back so your hands come up on top. Come back to the start position by doing all of the above backwards.

\section{LAWNMOWER}

Anchor band at ankle level and stand slightly wider than shoulder width, rotated 90 degrees away from the band. "Mini-Squat" and grab the band with your hand furthest from the anchored band. Allow the band to rotate hips/ spine towards the anchored band. Your feet should not move, but your chest should face the band. Pull back on band using your shoulder muscle, and rotate "trunk" back towards starting position, with band finishing at shoulder height.

\section{SIDE PLANK + SHOULDER ER}

Set up in side-lying with the arm underneath the body. Have a band wrapped around each hand. Lift into a side plank position, so the elbow and ankle are the only points of contact on ground. Emphasis on a straight line from ear, shoulder, hip, knee, and ankle from the front and top down view. Once in this position, "pin” top arm against the side of the body with shoulder blade pinched down and back. Rotate top hand towards the ceiling, while keeping top elbow pinched against body, and band anchored with lower hand. Rotate as high as possible without compensation, and slowly return to the starting position.

\section{QUADRUPED THORACIC ROTATION}

In kneeling with hands on the ground, rock back onto heels, as this will limit the motion in the low back. Put your palm on the base of your head and rotate to try to point your armpit towards the ceiling. Exhale on rotation.

Starting from the quadruped position, reach with your hand through the "window" created by the opposite arm and leg as far as possible.

These can be combined to increase and maintain spinal mobility: start your hand on the back of your head and rotate upward (as in the first video). On returning to neutral, remove your hand from your head and "thread the needle” by reaching as in the second video. Return to neutral quadruped position and repeat.

\section{SHOULDER IR AT 90/90 POSITION}

Anchor band behind the person so it is level with the top of the head. Hold band in hand of exercising arm, face away from band, and bend elbow to 90 degrees. Lift the arm so that it is parallel to the ground (90 degrees of elevation) and the elbow should be sticking straight out of the shoulder (not forward or behind). Stagger stance, with opposite foot in front as if throwing a ball. Engage core (pull ribs down), and slowly rotate the hand forward until it is parallel to the ground. Slowly return to the starting position and repeat.

\section{STANDING SCAPTION}

Hold the band in both hands and anchor under both feet. Start with both hands-on thighs, engage core and raise arms up in the scapular plane (approximately $45^{\circ}$ from frontal plane). Continue to raise arms in this position, with thumbs pointed towards the ceiling, until you reach approximately $100^{\circ}$. Slowly return to the starting position and repeat.

\section{STANDING CROSSBODY ADDUCTION POSTERIOR SHOULDER STRETCH (SHOULDER AGAINST WALL)}

Leaning thoracic against wall, bring right arm to $90^{\circ}$ of flexion in the sagittal plane with shoulder internal rotated. Place left arm over right arm and grasp your right elbow. Gradually put pressure through your left elbow to further pull your right arm into internal rotation. You will feel a pull in the outside/back of your shoulder. Now pull your right arm across your chest so your right hand goes under your left armpit. This will increase the stretch in the back of your 
shoulder. Hold 30 seconds and repeat.

\section{WALL WALK WITH THERABAND}

Position your band in a loop, without slack, bring the band out to shoulder width. With your hands placed at shoulder height and shoulder width alternate walking up the wall with the pinky side of the hand. Once your elbows get to the same level of your eyes (elbows should be slightly flexed), reverse the walk back down to the starting position.

\section{SEATED FOREARM PRONATION WITH THERABAND/CLX}

In a seated position place your forearm resting on your thigh so your hand/wrist is past your knee. With your palm up, position the elastic resistance from the outside of your foot and grasp it between your thumb and first finger continuing the band through your palm so it comes to a rest past your pinky finger. Grasping the band with palm up you will now pronate or try to turn palm down. You will feel the resistance from the band as you attempt to rotate your palm down.

\section{WRIST ULNAR DEVIATION WITH THERABAND/CLX}

With your shoulders flexed to 90 degrees and elbows extended, wrap the resistance band around both hands so palms are facing down, and the resistance band is already on mild stretch. With palms facing down try to bring both thumbs away from each other towards ulnar deviation. 